\title{
Effect of Gender on Computer Programming Courses Offered at Universities in Zimbabwe
}

\author{
${ }^{1}$ Gloria E. Mawere, \\ ${ }^{1}$ Lecturer, \\ Department of Accounting \& Information Systems, \\ Great Zimbabwe University, \\ Zimbabwe
}

\author{
2 Trust Mutero, \\ ${ }^{2}$ Lecturer, \\ Department of Accounting \& Information Systems, \\ Great Zimbabwe University, \\ Zimbabwe
}

\author{
${ }^{3}$ Clopas Kwenda \\ ${ }^{3}$ Lecturer, \\ Department of Accounting \& Information Systems, \\ Great Zimbabwe University, \\ Zimbabwe
}

\begin{abstract}
This Research Is Triggered By The Variability In Students' Performance In Computer Programming Courses At The Great Zimbabwe University (G.Z.U). Convenience Sampling Was Used To Select G.Z.U Among Other Thirteen Universities In Zimbabwe And The Research Focused On Information System Students. A Pretest Was Given Before The Commencements Of The Programming Test Followed By A Post-Test Given At The End Of The Semester. Pre-Test Results Showed No Significant Differences On Test Scores Between The Two Genders $(P>0.05)$. The Post-Test Results Of The Study Indicated That There Are Statistically Significant Differences $(P<0.05)$ In The Test Scores Between Female And Male Students. From The Results It Can Be Noted That Male Students Were Performing Better As Indicated By The Higher Mean Marks. It Can Be Concluded That There Are Gender Differences In The Performance Of Students In Programming Courses At Gzu. It Was Recommended That In Future Programming Lecturers Incorporate Gender Differences.
\end{abstract}

Keywords - Gender, computer programming, pre-test, post-test.

\section{INTRODUCTION}

Computer programming is an important discipline as far as computer systems is concerned. It can be regarded as the kernel of computer systems because they make computers do what they are designed to do. When it comes to the notion of computer programming it is interesting to note that in the $20^{\text {th }}$ century the first computer programmers were females and in number they were 80 , they were mandated to calculate ballistics trajectories on a computer during World War II at the University of Pennsylvania(Morris \& Trushell, 2014).In the late 1950s and early 1960s half of the computer programmers and systems analysts were women but the number however declined in the mid-1980s to about onefifth(Newton \& Haslam, 1988). The reasons suggested by Newton could be as a result of different number of factors and some have been refuted to the notion that it was due to changes in technology or that woman lacked requisite intellectual faculties.

A very surprising notion is that the field of IT is associated with masculine hence it is a fraternity which is maledominated (Brosnan, 1998). The notion that technology is made by men for men ('boys and their toys') and that the world of computing is not female-friendly is supported by (Sanders, 2005) who draws attention to research which has suggested that:

'The violent language of technology may be invisible to males but can be a problem for females. Consider hard disc, hard drive, reboot, cold boot, hits, permanent fatal error, and so forth. Recreational or even educational software for children often includes title words such as "attack" or "war",

In general the number of women who pursue education and occupation in IT related fields is less than that of male counter parts(Shashaani, 1997). The percentage of females studying computer science or information systems (in which there are so many computer programming courses in them) has declined at a time when the proportion of women at the college level outnumbered the proportion of men(Leverson, 1991). As we are living in the information age era there is great need to increase the enrollment and participation of students to computer science courses since the employment for qualified computer scientists and programmers has increased resulting in shortage of good quality professionals in the field(Hutchinson, Moskal, Cooper, \& Damm, 2008). It is against this backdrop of more males participating in IT related course, that there is need to determine the effect of gender on student's performance in programming courses at Great Zimbabwe University.

\section{MATERIALS AND METHODS}

In this study, a comparative experimental design was used to assess if there is a significance differences in computer programming mastery between male and female students. In this case, effectiveness was determined through concept mastery and exam mark. Comparative experiments are designed to determine the differences between control and treatment groups (Verial, 2015) and for the study the study design is indicated in figure 1 . Convenience sampling was used to select Great Zimbabwe University from the thirteen universities that are found in Zimbabwe because that is where the author is currently discharging his duties and that 
Great Zimbabwe University is a state university it therefore implies that its administrative processes is just the same as with other state universities. Specifically for this study the target population was students doing Bachelor of Science degree in Information Systems who are currently in their second year first semester (2:1). That is the level where computer programming courses are taught.

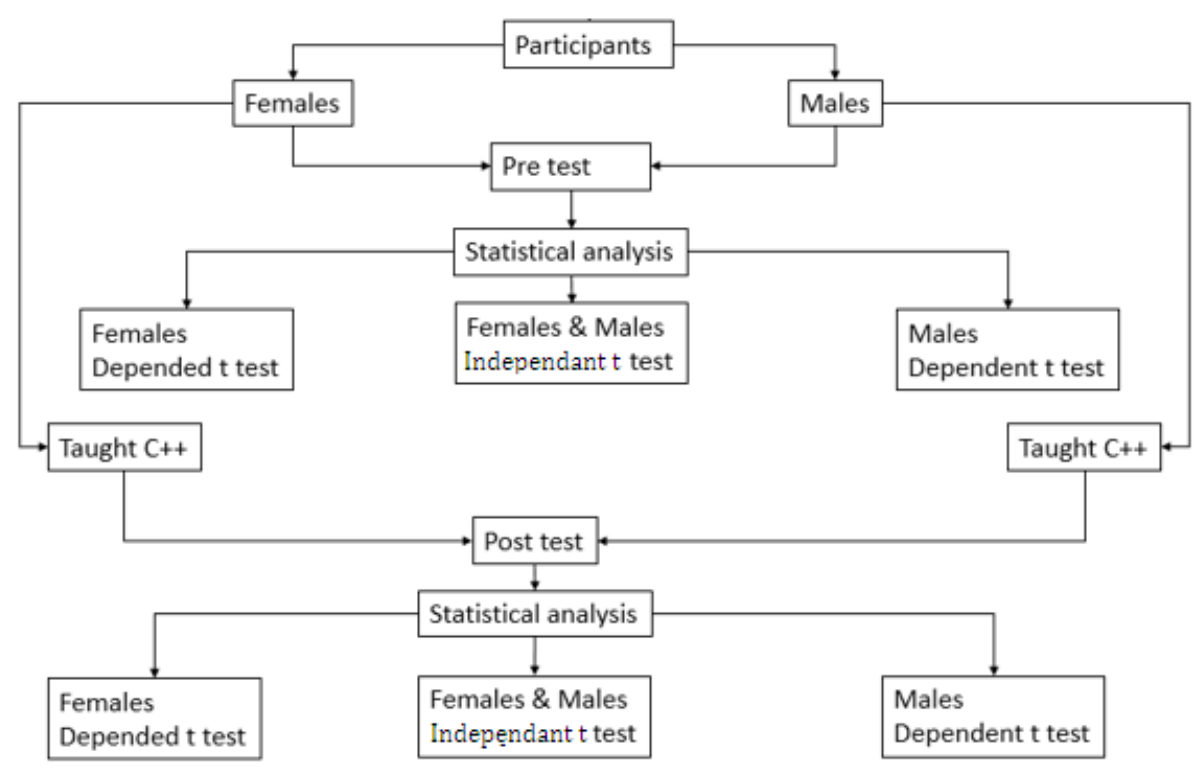

Figure 1 Research design

In order to determine the effect of gender on computer programming performance, the researcher administered a pre-test before the students were taught using $\mathrm{C}++$ object oriented programming language. A pre-test was given to both groups on the 8th of September 2016 that is their first semester of 2016. Then after that both students were taught and guided on the $\mathrm{C}++$ objected oriented programming language. Lastly a post-test was given on the 1st of November of 2016 to assess the effect of gender on student performance in programming language.

The tests were then marked by the researcher and scores recorded for analysis. The assessment tests were suitable because of the following advantages: use of both pre-test and post-test enabled the measurement of differences in performances between male and female students, thus eliminating the effects of prior knowledge of the students and ensuring internal validity of the experiment results.

\section{STATISTICAL ANALYSIS}

In order to test for the differences in the mean marks of the students according to gender, an independent t-test was used. To test for the variability in the marks within the gender, the dependent t-test was used. The dependent variable was mean mark whilst the grouping variable was the groups (males and females). All the tests and graphs were done in MS. Excel 2013.

\section{Pre-test}

Before the students were taught programming, they were given an introduction to programming as pre-test. Results of the pre-test are presented in Figure 2. The results indicated that there were no significant differences in the performance of between male and female students $(\mathrm{t}=-1.1169, \mathrm{df}=20$, $\mathrm{p}=0.1389$ ). Thus the male and female students performed the same in the theoretical programming taught course. 


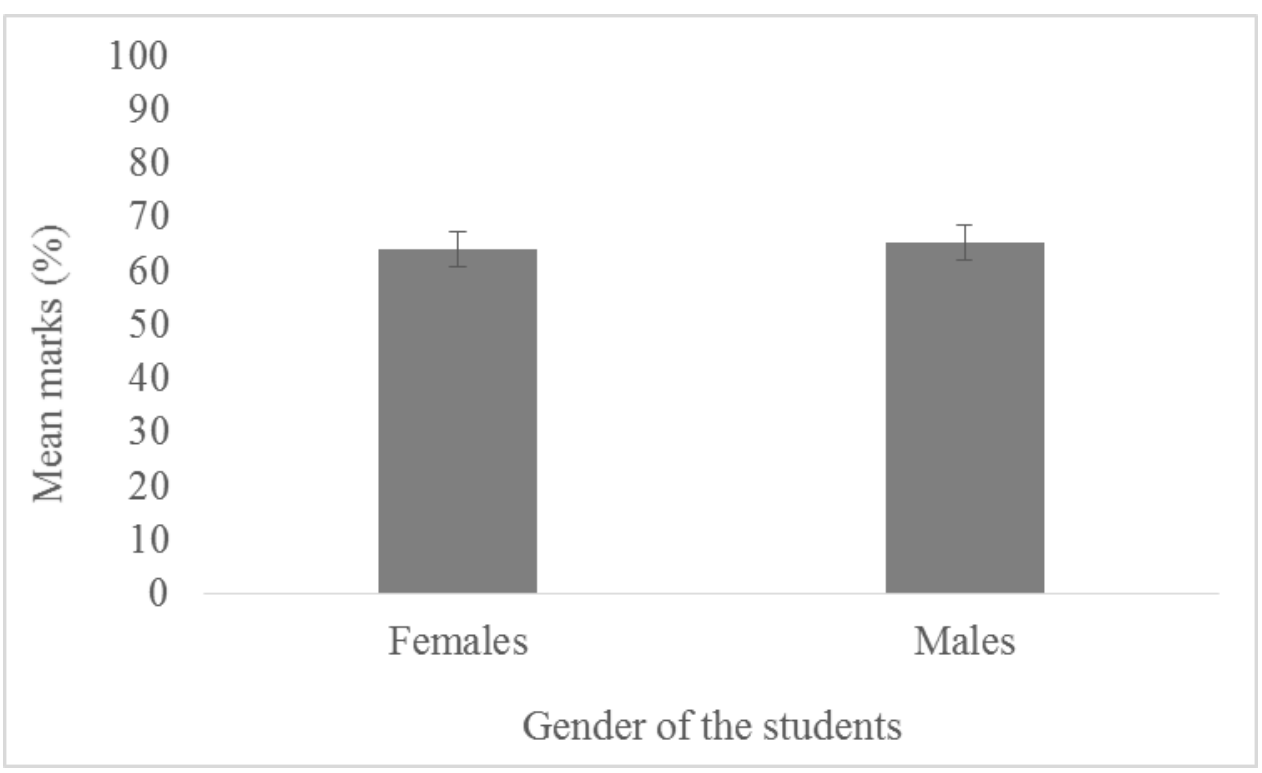

Figure 2 Pre-test mean marks for the students by gender

Post test

After the students were taught programming, they were subjected to programming exercise and the results are shown in Figure 2. In this study it can be stated that there are significant differences between males and females in programming $(t=-1.7286, d f=20, p=0.04)$. Thus from the graph it can be noted that the average marks for males were significantly higher than the marks got by females.

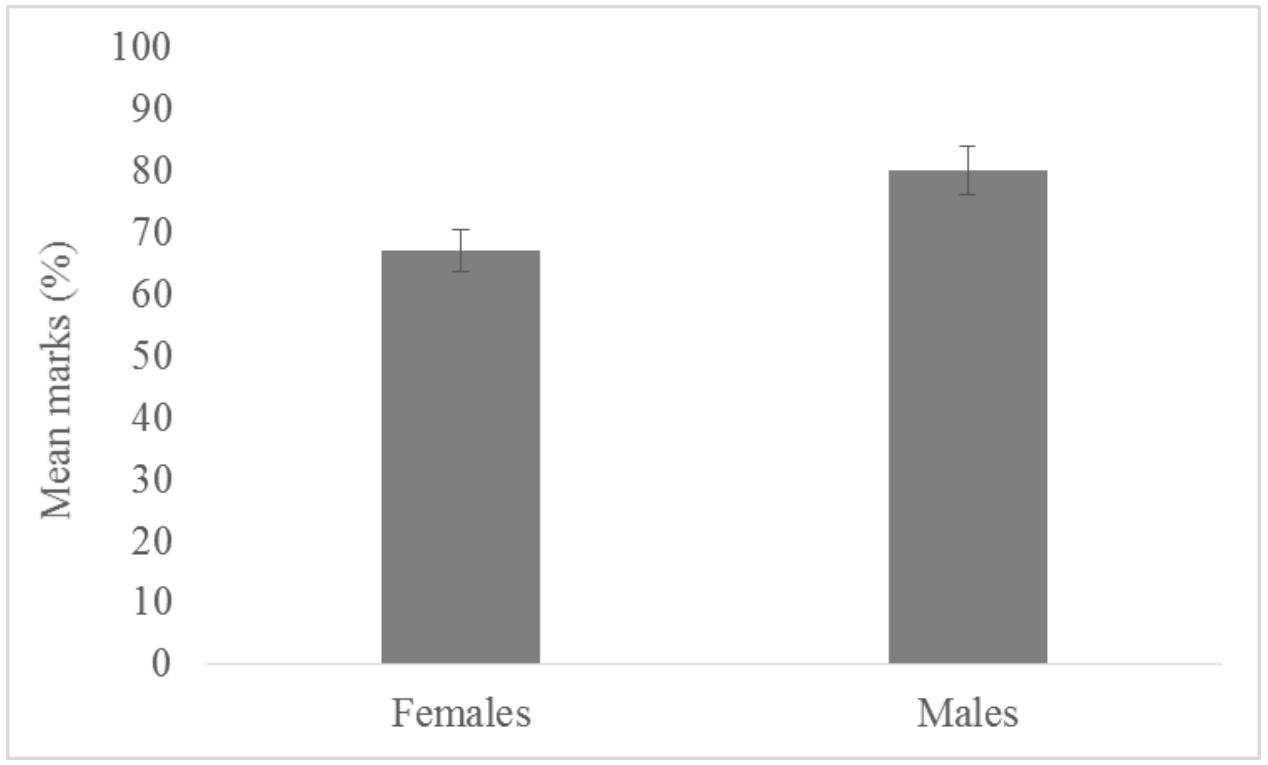

Figure 3 Post-test mean marks for the students by gender

Since the study indicated that there were significant differences between males and females in programming at Great Zimbabwe University. However there was need to determine if there was any significant differences within males and females before and after being taught programming. Results of this study indicated that there were significant differences in the mean marks for female students before and after being taught programming ( $\mathrm{t}=$ 7.1071, $\mathrm{df}=10, \mathrm{p}=0.000$ ). Thus it can be stated that females scored more after being taught computer programming. 


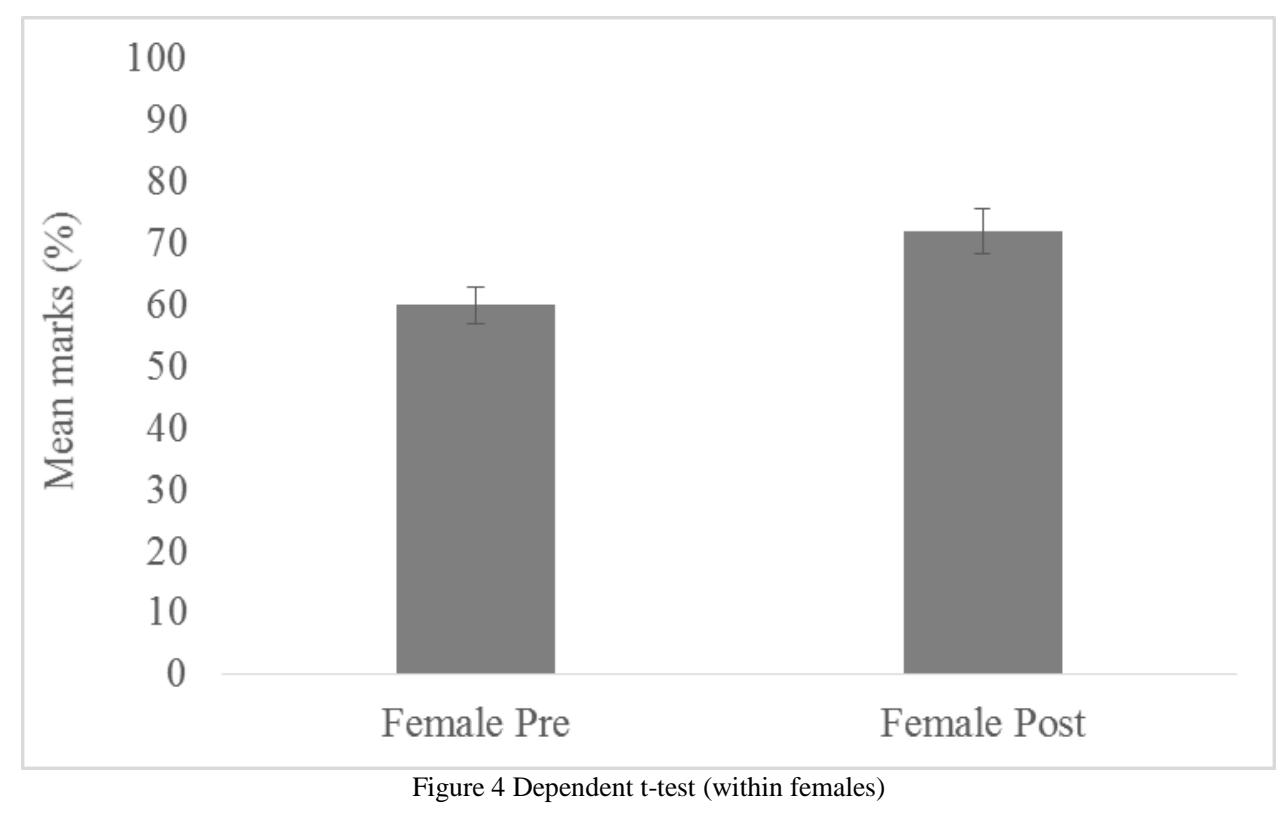

Since the study indicated that there were significant differences within females programming at Great Zimbabwe University. Results of this study indicated that there were significant differences in the mean marks for male students before and after being taught programming $(\mathrm{t}=-5.313$, $\mathrm{df}=10, \mathrm{p}=0.000$ ). Thus it can be stated that males scored more after being taught computer programming.

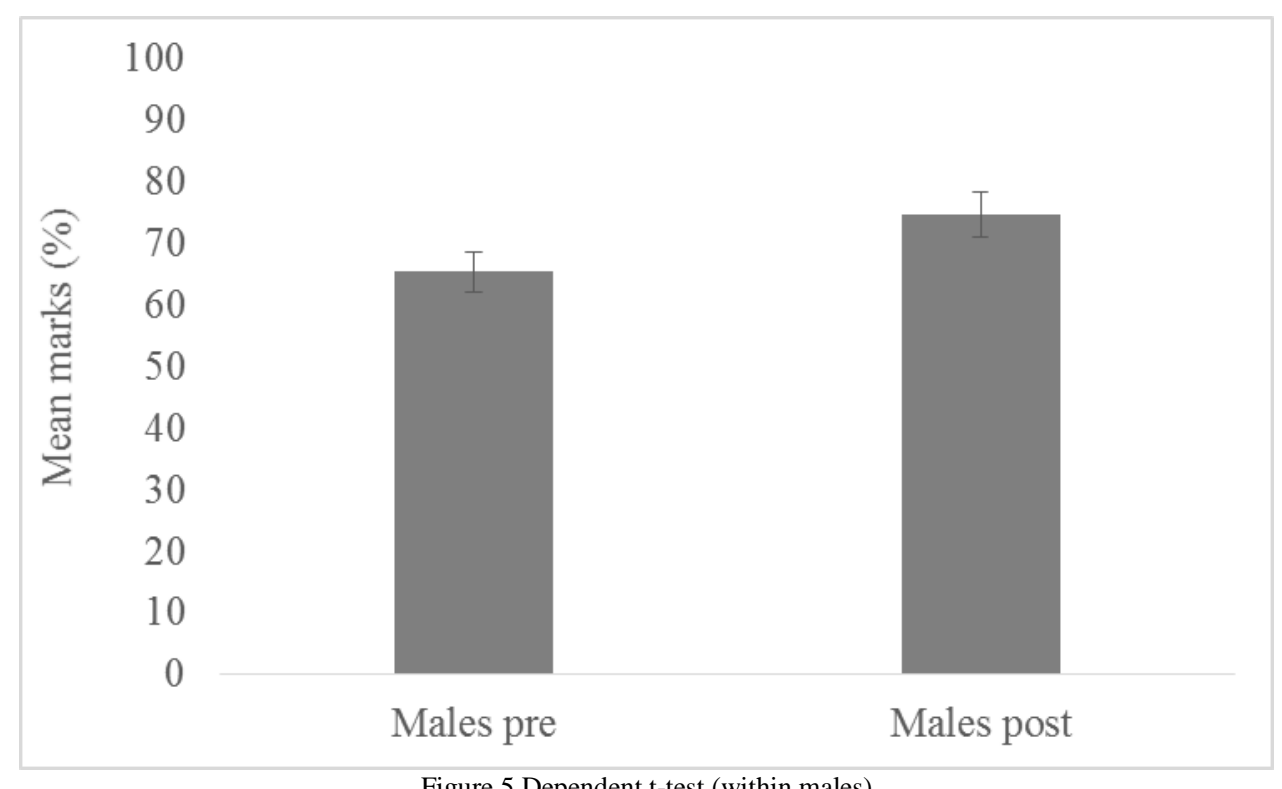

\section{DISCUSSION}

Pre-test results showed that there are no significant differences in performance between female and male students on object oriented programming course taught using $\mathrm{c}^{++}$. The introductory object oriented course prefaced the required mandatory concepts which are very easy to understand and master. As is always the case with many courses that the introductory part is not always demanding and does not require an in depth knowledge. This reason could help to explain why there was no significance difference. The lack of significant differences in the pre-test phase of this study is not surprising as the students will be answering their questions without the influence of the different e-learning software packages.
However, the significant differences that exist in the posttest phase can be alluded to the effect that Female students are interested more in the use of computers than in doing programming, whereas male students see computer science mainly as a programming activity(Dorian \& Gunawarden, 2010). Bruce Byfield makes it sound like a lot of the gender gap was because male prommers are much more willing to spend their free time programming. This makes some sense if you stick to the gender stereotypes that men have more enthusiasm for technical subjects, and that women think of it as "just a job,"(J. James, 2010).

There was significant differences in the mean marks for female students before and after being taught programming $(t=-7.1071, \quad d f=10, \quad p=0.000)$. This shows that female 
students did not stay the same in terms of knowledge gain, reason could be attributed to the way they were taught. The instructor implored the paired programming technique during the administration exercise. Research has shown that paired programming(Lecia \& McGrath, 2008)

- Reduces the so-called “confidence gap” between female and male students, while increasing the programming confidence of all students;

Results of this study indicated that there were significant differences in the mean marks for male students before and after being taught programming $(\mathrm{t}=-5.313, \mathrm{df}=10, \mathrm{p}=0.000)$. Thus it can be stated that males scored more after being taught computer programming. This could be as result of the fact that most men are not moronic technical subjects and they want to be the master of their own destiny. This notion can also be substantiated by James who attributed the attributes of a real computer programmer. He said(M. James, n.d.)

"Take a typical computer programmer as an example. He (as the overwhelming majority of computer programmers are male) is a smart, studious human being that spends the majority of his day making the computer perform magical calculations using his own magical code.”

\section{RECOMMENDATION}

To break the gender imbalance in computer programming for female university students, there are newly computer programming organization called Django girls (tailor made for females only) which are mandated to improve female programming skills. Therefore females' students are highly encouraged to register to be enrolled in such organization. Also incorporating the paired programming concept in teaching where by a pair is established by mixing female and male students to accomplish a programming task. The assumption is that male students will work with female students in trying to improve their computer programming capabilities.

\section{REFERENCES}

[1] Brosnan, M. J. (1998). The impact of computer anxiety and self-efficacy upon performance, (March), 223-234.

[2] Dorian, S., \& Gunawarden, E. (2010). Gender differences in the use of computers, programming, and peer interactions in computer science classrooms. Computer Science Education, 20(4), 283-300. Retrieved from http://www.tandfonline.com/doi/abs/10.1080/08993408.2010. 527691 ?src $=$ recsys\&journalCode $=$ ncse20

[3] Hutchinson, A., Moskal, S., Cooper, d, \& Damm, W. (2008). Impact of the Alice curriculumn on community college students attitude and learning with respect to computer science. In mpact of the Alice curriculumn on community college students attitude and learning with respect to computer science. American society for engineering education Pittsburgh, PA.

[4] James, J. (2010). IT Gender group: where are the female programmers. Retrieved May 1, 2017, from http://www.techrepublic.com/blog/software-engineer/itgender-gap-where-are-the-female-programmers/

[5] James, M. (n.d.). Why computer programmers can’t pick up women. Retrieved May 1, 2017, from https://mavericktraveler.com/why-computer-programmerscant-pickup-women/

[6] Lecia, B., \& McGrath, C. (2008). National Center for Women \& Information Technology PROMISING PRACTICES Pair Programming ( Case Study 1 ) National Center for Women \& Information Technology PROMISING PRACTICES How Do You Retain Women through Collaborative Learning? National Center for Women \& Information Technology P R O M I S I N G P R A C T I C E S, (2001), 2007-2008.

[7] Leverson, N. . (1991). Educational pipeline issues for women. Computing Research News, 1-11.

[8] Morris, D., \& Trushell, J. (2014). Computer programming, ICT and gender in the classroom: a male-dominated domain or a female preserve?, 4(1), 4-9.

[9] Newton, P., \& Haslam, S. (1988). Computing: an ideal occupation for woman. In Proceedings of the first National Wic conference. University of Lancester.

[10] Sanders, J. (2005). Gender and Technology in Education: A Research Review, 6. Retrieved from www.umbc.edu/cwit/itgenderbib/

[11] Shashaani, L. (1997). J.Educational Computing Research. J.Educational Computing Research, 16(1), 37-51. 